\title{
Pyridine(diimine) Chelate Hydrogenation in a Molybdenum Nitrido Ethylene Complex
}

\author{
Máté J. Bezdek and Paul J. Chirik* \\ Department of Chemistry, Frick Laboratory \\ Princeton University, Princeton, NJ 08544, USA \\ pchirik@princeton.edu
}

\section{Table of Contents}

$\begin{array}{ll}\text { I. General Considerations } & \text { S2 }\end{array}$

II. Preparation of Molybdenum Complexes S5

$\begin{array}{ll}\text { III. Additional Reactions } & \text { S8 }\end{array}$

$\begin{array}{ll}\text { IV. NMR Data } & \text { S9 }\end{array}$

$\begin{array}{ll}\text { V. EPR Data } & \text { S11 }\end{array}$

$\begin{array}{ll}\text { VI. Electronic Absorption Data } & \text { S12 }\end{array}$

$\begin{array}{ll}\text { VII. Electronic Structure Discussion } & \text { S13 }\end{array}$

$\begin{array}{lr}\text { VIII. DFT Input Example } & \text { S14 }\end{array}$

$\begin{array}{ll}\text { IX. DFT-Computed Energies } & \text { S15 }\end{array}$

$\begin{array}{ll}\text { X. References } & \text { S16 }\end{array}$ 


\section{General Considerations}

All air- and moisture-sensitive manipulations were carried out using vacuum line, Schlenk and cannula techniques or in an MBraun inert atmosphere (nitrogen) dry box unless otherwise noted. The solvents used for air- and moisture-sensitive manipulations were dried and deoxygenated using literature procedures. ${ }^{1}$ Celite was dried at $200{ }^{\circ} \mathrm{C}$ under vacuum for 3 days prior to use. Deuterated solvents for NMR spectroscopy were distilled from sodium metal under an atmosphere of argon and stored over $4 \AA$ molecular sieves. Hydrogen gas was purchased from Airgas National Welders and passed through a column of $\mathrm{MnO}_{2}$ supported on vermiculite and $3 \AA$ molecular sieves prior to use on a Schlenk manifold. The following compounds were prepared according to literature procedures: $\left[\left({ }^{\mathrm{PPr} P D I}\right) \mathrm{MoCl}_{3}\right] \quad(\mathrm{PrPDI}=2,6-(2,6-$ $\left.\left.\mathrm{iPr}_{2} \mathrm{C}_{6} \mathrm{H}_{3} \mathrm{~N}=\mathrm{CMe}\right)_{2} \mathrm{C}_{5} \mathrm{H}_{3} \mathrm{~N}\right),{ }^{2}\left[\left({ }^{\mathrm{Pr} P D I}\right) \mathrm{Mo}\left(\eta^{6}-\mathrm{C}_{6} \mathrm{H}_{6}\right)\right],{ }^{2}\left({ }^{\text {(PrPDI }}\right) \mathrm{Mo}(\mathrm{N})\left(\mathrm{C}_{2} \mathrm{H}_{4}\right)\left\{\left[\mathbf{1}-(\mathrm{N})\left(\mathbf{n}^{2}-\mathrm{C}_{2} \mathrm{H}_{4}\right)\right]\right\},{ }^{2}\left[\left(\eta^{5}-\right.\right.$ $\left.\left.\mathrm{C}_{5} \mathrm{Me}_{5}\right)(\mathrm{py}-\mathrm{Ph}) \mathrm{Rh}(\mathrm{H})\right]\left([\mathbf{R h}-\mathrm{H}] ; \mathrm{py}-\mathrm{Ph}=2\right.$-phenylpyridine). ${ }^{3}$

${ }^{1} \mathrm{H}$ NMR spectra were recorded on a Bruker AVANCE 500 spectrometer operating at 500.46 MHz. ${ }^{13} \mathrm{C}$ NMR spectra were recorded on a Bruker AVANCE 500 spectrometer operating at 125.85 MHz. ${ }^{15} \mathrm{~N}$ NMR spectra were recorded on a Bruker 500 spectrometer operating at $50.663 \mathrm{MHz}$, and ${ }^{15} \mathrm{~N}$ chemical shifts are reported relative to liquid $\mathrm{NH}_{3}$ using an external standard. All ${ }^{1} \mathrm{H}$ and ${ }^{13} \mathrm{C}$ NMR chemical shifts are reported in ppm relative to $\mathrm{SiMe}_{4}$ using the ${ }^{1} \mathrm{H}$ (benzene- $d_{6}: 7.16 \mathrm{ppm}$ ) and ${ }^{13} \mathrm{C}$ (benzene- $d_{6}: 128.06 \mathrm{ppm}$ ) chemical shifts of the solvent as a standard. ${ }^{1} \mathrm{H}$ NMR data for diamagnetic compounds are reported as follows: chemical shift, multiplicity $(\mathrm{s}=$ singlet, $\mathrm{d}=$ doublet, $\mathrm{t}=$ triplet, $\mathrm{q}=$ quartet, $\mathrm{p}=$ pentet, $\mathrm{br}=$ broad, $\mathrm{m}=$ multiplet, app $=$ apparent, obsc $=$ obscured $)$, coupling constants $(\mathrm{Hz})$, integration, assignment.

Continuous wave EPR spectra were recorded on an X-band Bruker EMXPlus spectrometer equipped with an EMX standard resonator and a Bruker PremiumX microwave bridge. The spectra were simulated using EasySpin for MATLAB. ${ }^{4}$ 
Elemental analyses were performed at Robinson Microlit Laboratories, Inc., in Ledgewood, NJ.

Single crystals suitable for X-ray diffraction were coated with polyisobutylene oil in a drybox, transferred to a nylon loop and then quickly transferred to the goniometer head of a Bruker VENTURE D8 PHOTON 100 diffractometer equipped with a molybdenum X-ray tube $(\lambda=$ $0.71073 \AA)$ and a Cu X-ray tube $(\lambda=1.54178 \AA)$. Preliminary data revealed the crystal system. The data collection strategy was optimized for completeness and redundancy using the Bruker COSMO software suite. The space group was identified, and the data were processed using the Bruker SAINT+ program and corrected for absorption using SADABS. The structures were solved using direct methods (SHELXS) completed by subsequent Fourier synthesis and refined by full-matrix least-squares procedures.

UV-visible absorption spectra were recorded on an Agilent 8453 diode array UV/Vis spectrophotometer. Samples were charged into a quartz cuvette fitted with a J-Young Teflon cap in a glovebox and transferred to the spectrometer to record absorption spectra.

All DFT calculations were performed with the ORCA program package in the gas phase. ${ }^{5}$ The geometry optimizations of the complexes and single-point calculations on the optimized geometries were carried out at the $\mathrm{B}^{2} \mathrm{LYP}^{6}$ or $\mathrm{PW}^{\mathrm{B}} 95^{7}$ level of DFT. The all-electron Gaussian basis sets were those developed by the Ahlrichs group. ${ }^{8}$ Triple- $\zeta$ quality basis sets def2-TZVP with one set of polarization functions on molybdenum, phosphorous and nitrogen were used. For the carbon and hydrogen atoms, slightly smaller polarized split-valence def2-SV(P) basis sets were used that were of double- $\zeta$ quality in the valence region and contained a polarizing set of $d$ functions on the non-hydrogen atoms. Auxiliary basis sets to expand the electron density in the resolution-of-the-identity (RIJCOSX) ${ }^{9}$ approach were chosen to match the orbital basis. ${ }^{10}$ Numerical frequencies were calculated at the same level of theory to confirm the optimized geometries (no imaginary frequencies) and to derive thermochemical data. Bond 
dissociation free energies were computed at standard conditions of 1 atm and $25{ }^{\circ} \mathrm{C}$ including corrections for vibrational zero-point energy, as well as contributions from translational, rotational, and vibrational modes to the energy and entropy of the homolytic bond cleavage process. For molecules containing a molybdenum atom, the 0th order regular approximation (ZORA) was applied. ${ }^{11}$ In this case, the relevant basis sets were replaced by their relativistically recontracted versions. ${ }^{12}$ The electronic energy of $\mathrm{H} \cdot$, utilized in the calculation of bond dissociation free energies, at the present level of theory is $312 \mathrm{kcal} / \mathrm{mol}$. Localized orbital bonding analysis (LOBA) ${ }^{13}$ was performed on Molden output files using the Multiwfn program package. ${ }^{14}$ 


\section{Preparation of Molybdenum Complexes}
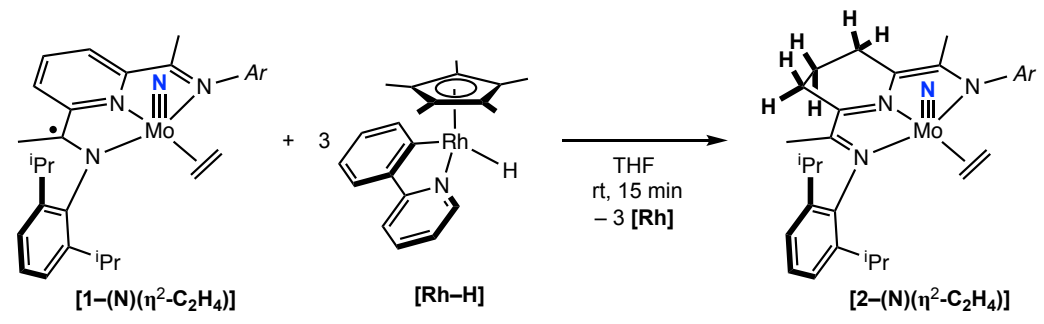

Preparation of [2-(N)( $\left.\left.\eta^{2}-\mathrm{C}_{2} \mathrm{H}_{4}\right)\right]$ (Method A): In the glovebox, a $20 \mathrm{~mL}$ scintillation vial was charged with a magnetic stir bar and $0.021 \mathrm{~g}(0.034 \mathrm{mmol})$ of $\left[1-(\mathrm{N})\left(\eta^{2}-\mathrm{C}_{2} \mathrm{H}_{4}\right)\right]$ dissolved in $1 \mathrm{~mL}$ of THF. To the stirring solution, $0.040 \mathrm{~g}(0.103 \mathrm{mmol})$ of $[\mathbf{R h}-\mathrm{H}]$ was added. The reaction was stirred at room temperature for 15 minutes during which time a color change from dark orange to dark green was observed. The solvent was removed in vacuo, the dark green residue was suspended in $3 \mathrm{~mL}$ of toluene and filtered through a pad of Celite. The dark green filtrate was layered with pentane $(5 \mathrm{~mL})$ and stood at $-35{ }^{\circ} \mathrm{C}$ for 3 days. After this time, the molybdenum product-containing green-blue supernatant was decanted away from the orange-yellow crystals, and the solvent of the supernatant was removed in vacuo. The resulting dark blue residue was extracted with $3 \mathrm{~mL}$ of pentane, filtered through a pad of Celite and stood at $-35^{\circ} \mathrm{C}$ for $18 \mathrm{~h}$. The supernatant was decanted, and the blue crystalline material obtained was dried in

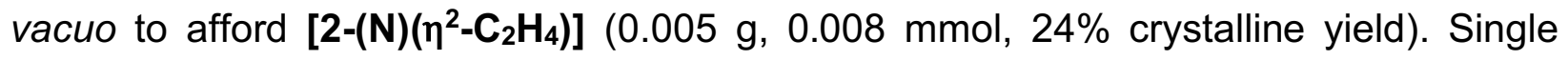
crystals suitable for X-Ray diffraction studies were obtained from a concentrated pentane solution of $\left[2-(\mathbf{N})\left(\eta^{2}-\mathrm{C}_{2} \mathrm{H}_{4}\right)\right]$ at $-35^{\circ} \mathrm{C}$. The ${ }^{15} \mathrm{~N}$ isotopologue $\left[2-\left({ }^{15} \mathrm{~N}\right)\left(\eta^{2}-\mathrm{C}_{2} \mathrm{H}_{4}\right)\right]$ was prepared using an identical procedure with the exception that $\left[1-\left({ }^{15} \mathrm{~N}\right)\left(\eta^{2}-\mathrm{C}_{2} \mathrm{H}_{4}\right)\right]$

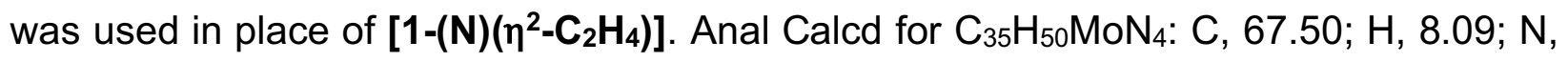
9.00. Found: $\mathrm{C}, 67.10 ; \mathrm{H}, 7.82 ; \mathrm{N}, 8.71 .{ }^{1} \mathrm{H}$ NMR (benzene- $\left.d_{6}, 23{ }^{\circ} \mathrm{C}\right): \delta 7.21\left(\mathrm{~d},{ }^{3} \mathrm{~J}_{\mathrm{H}-\mathrm{H}}=\right.$ $7.6 \mathrm{~Hz}, 2 \mathrm{H}$, aryl-CH), $7.13\left(\mathrm{t},{ }^{3} \mathrm{~J}_{\mathrm{H}-\mathrm{H}}=6.6 \mathrm{~Hz}, 2 \mathrm{H}\right.$, aryl-CH), $7.05(\mathrm{~d}, \mathrm{~J}=7.4 \mathrm{~Hz}, 2 \mathrm{H}$, aryl- 
$\mathrm{CH}), 4.07-3.97(\mathrm{~m}, 2 \mathrm{H}, \mathrm{iPr} \mathrm{CH}), 2.64-2.55(\mathrm{~m}, 2 \mathrm{H}, \mathrm{iPr} \mathrm{CH}), 2.39\left(\mathrm{dd},{ }^{3} \mathrm{~J}_{\mathrm{H}-\mathrm{H}, \text { trans }}=12.4\right.$ $\left.\mathrm{Hz},{ }^{2} \mathrm{~J}_{\mathrm{H}-\mathrm{H}, \mathrm{gem}}=4.9 \mathrm{~Hz}, 2 \mathrm{H}, \mathrm{C}_{2} \mathrm{H}_{4}\right), 2.26-2.19\left(\mathrm{~m}, 2 \mathrm{H}\right.$, backbone $\left.\mathrm{CH}_{2}\right), 2.01-1.91(\mathrm{~m}, 2 \mathrm{H}$, backbone $\mathrm{CH}_{2}$ ), $1.66\left(\mathrm{~s}, 6 \mathrm{H}\right.$, backbone $\left.\mathrm{CH}_{3}\right), 1.43\left(\mathrm{~d},{ }^{3} \mathrm{~J}_{\mathrm{H}-\mathrm{H}}=6.7 \mathrm{~Hz}, 6 \mathrm{H}, \operatorname{iPr} \mathrm{CH}_{3}\right)$, 1.28-1.21 (m, 2H, backbone $\left.\mathrm{CH}_{2}\right), 1.19\left(\mathrm{~d},{ }^{3} \mathrm{~J}_{\mathrm{H}-\mathrm{H}}=6.9 \mathrm{~Hz}, 6 \mathrm{H}, \operatorname{iPr} \mathrm{CH}_{3}\right), 1.06\left(\mathrm{dd},{ }^{3} \mathrm{~J}_{\mathrm{H}-\mathrm{H}}\right.$, trans $\left.=12.4 \mathrm{~Hz},{ }^{2} \mathrm{~J}_{\mathrm{H}-\mathrm{H}, \mathrm{gem}}=4.9 \mathrm{~Hz}, 2 \mathrm{H}, \mathrm{C}_{2} \mathrm{H}_{4}\right), 1.01\left(\mathrm{~d},{ }^{3} \mathrm{~J}_{\mathrm{H}-\mathrm{H}}=6.9 \mathrm{~Hz}, 6 \mathrm{H}, \mathrm{iPr} \mathrm{CH}_{3}\right), 0.98$ $\left(\mathrm{d},{ }^{3} \mathrm{H}_{\mathrm{H}-\mathrm{H}}=6.9 \mathrm{~Hz}, 6 \mathrm{H}, \operatorname{iPr} \mathrm{CH}_{3}\right) .{ }^{13} \mathrm{C}\left\{{ }^{1} \mathrm{H}\right\} \mathrm{NMR}$ (benzene- $d_{6}, 23^{\circ} \mathrm{C}$ ): $\delta 174.51$ (ipso $\mathrm{N}-\mathrm{C}$ ), 147.26 (ipso-aryl $\mathrm{N}-\mathrm{C}$ ), 143.37 (iPr ipso aryl-C), 138.97 (iPr ipso aryl-C), 128.97 (ipso $\mathrm{N}-\mathrm{C}), 126.06(\operatorname{aryl}-\mathrm{CH}), 124.92(\operatorname{aryl}-\mathrm{CH}), 123.01$ (aryl- $\mathrm{CH}), 51.71\left(\mathrm{C}_{2} \mathrm{H}_{4}\right), 28.80(\mathrm{iPr}$ $\mathrm{CH}), 27.74$ (iPr CH), $25.16\left(\mathrm{iPr} \mathrm{CH}_{3}\right), 25.13$ (backbone $\left.\mathrm{CH}_{2}\right), 24.48\left(\mathrm{iPr} \mathrm{CH}_{3}\right), 24.31(\mathrm{iPr}$ $\mathrm{CH}_{3}$ ), $23.58\left(\right.$ iPr $\mathrm{CH}_{3}$ ), 22.74 (backbone $\mathrm{CH}_{2}$ ), 19.01 (backbone $\mathrm{CH}_{3}$ ). ${ }^{15} \mathrm{~N}\left\{{ }^{1} \mathrm{H}\right\} \mathrm{NMR}$ (benzene- $\left.d_{6}, 23^{\circ} \mathrm{C}\right): \delta 1040(\mathrm{~s}$, nitrido $N$ ).

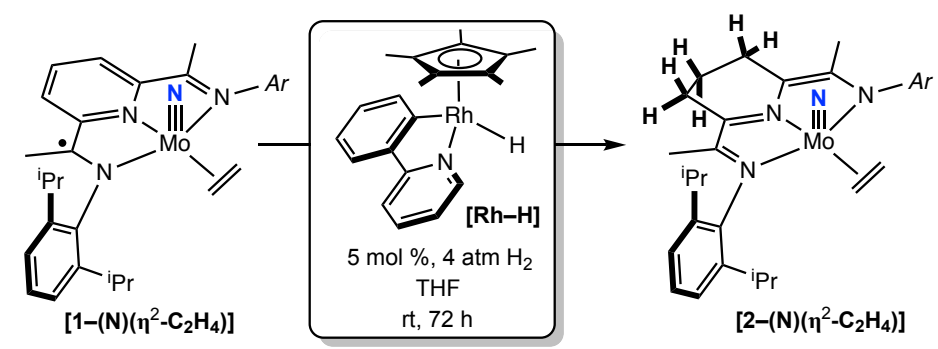

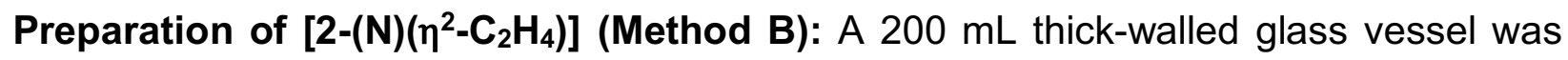
charged with a magnetic stir bar, $0.022 \mathrm{~g}(0.035 \mathrm{mmol})$ of $\left[1-(\mathrm{N})\left(\eta^{2}-\mathrm{C}_{2} \mathrm{H}_{4}\right)\right], 0.70 \mathrm{mg}$ (1.78 $\mu \mathrm{mol}$, added as $0.5 \mathrm{M}$ stock solution in THF) of $[\mathrm{Rh}-\mathrm{H}]$ and $2 \mathrm{~mL}$ of THF. The vessel was sealed and connected to the high vacuum line where the headspace was evacuated and $\mathrm{H}_{2}\left(1 \mathrm{~atm}\right.$ at $-196{ }^{\circ} \mathrm{C} ; \sim 4$ atm at $\left.23^{\circ} \mathrm{C}\right)$ was admitted. The vessel was sealed and stirred at room temperature for $72 \mathrm{~h}$. A series of color changes were noted over the course of the reaction starting from dark pink-red to orange, maroon, black, blue-green and finally dark blue, indicating reaction completeness. The vessel was then 
brought back into the glovebox where the reaction mixture was transferred to a $20 \mathrm{~mL}$ scintillation vial and the solvent was removed in vacuo. The dark blue residue was extracted with pentane $(3 \times 2 \mathrm{~mL})$ and the combined extracts were filtered through a pad of Celite. The filtrate was concentrated to $3 \mathrm{~mL}$ and stood at $-35{ }^{\circ} \mathrm{C}$ for $48 \mathrm{~h}$. The crystalline solids were isolated, washed with cold $\left(-35^{\circ} \mathrm{C}\right)$ pentane and dried in vacuo to afford [2-(N)( $\left.\left.\eta^{2}-\mathbf{C}_{2} \mathrm{H}_{4}\right)\right]$ as a dark blue solid $(0.014 \mathrm{~g}, 0.022 \mathrm{mmol}, 63 \%)$.

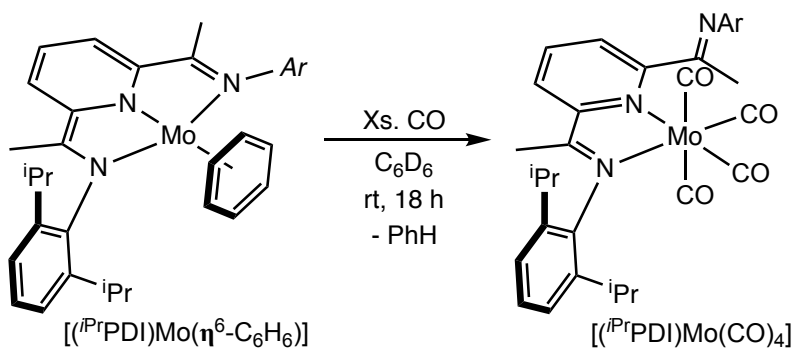

Alternative preparation of $\left[\left({ }^{\mathrm{PP} P D I}\right) \mathrm{Mo}(\mathrm{CO})_{4}\right]$. In the glovebox, a Teflon-capped $\mathrm{J}$ Young NMR tube was charged with $\left[\left({ }^{\mathrm{Pr} P D I}\right) \mathrm{Mo}\left(\eta^{6}-\mathrm{C}_{6} \mathrm{H}_{6}\right)\right](0.050 \mathrm{~g}, 0.076 \mathrm{mmol})$ dissolved in $0.6 \mathrm{~mL}$ benzene- $d_{6}$. The tube was sealed and connected to the high vacuum line, where the headspace was evacuated and $\mathrm{CO}\left(1 \mathrm{~atm}\right.$ at $\left.-78{ }^{\circ} \mathrm{C}\right)$ was admitted. The tube was sealed and was rotated end-over-end at room temperature for $18 \mathrm{~h}$. During this time, the headspace of the tube was re-charged with CO (1 atm, -78 $\left.{ }^{\circ} \mathrm{C}\right)$ three times at the first three-hour intervals $(3 \mathrm{~h}, 6 \mathrm{~h}$, and $9 \mathrm{~h})$ and a color change from brown to red-violet was observed. After $18 \mathrm{~h}$ of stirring at room temperature, complete conversion of $\left[\left({ }^{(\mathrm{Pr} P D I}\right) \mathrm{Mo}\left(\eta^{6}-\mathrm{C}_{6} \mathrm{H}_{6}\right)\right]$ was observed by ${ }^{1} \mathrm{H}$ NMR spectroscopy. The tube was brought then back into the glovebox and the reaction solvent was removed in vacuo. The residue was washed with cold pentane $\left(3 \times 5 \mathrm{~mL},-35^{\circ} \mathrm{C}\right)$ and dried in vacuo to yield the product as a red solid $(0.048 \mathrm{~g}, 0.070 \mathrm{mmol}, 92 \%)$. The ${ }^{1} \mathrm{H}$ NMR and IR characterization data matched those previously reported. ${ }^{15}$ 


\section{Additional Reactions}
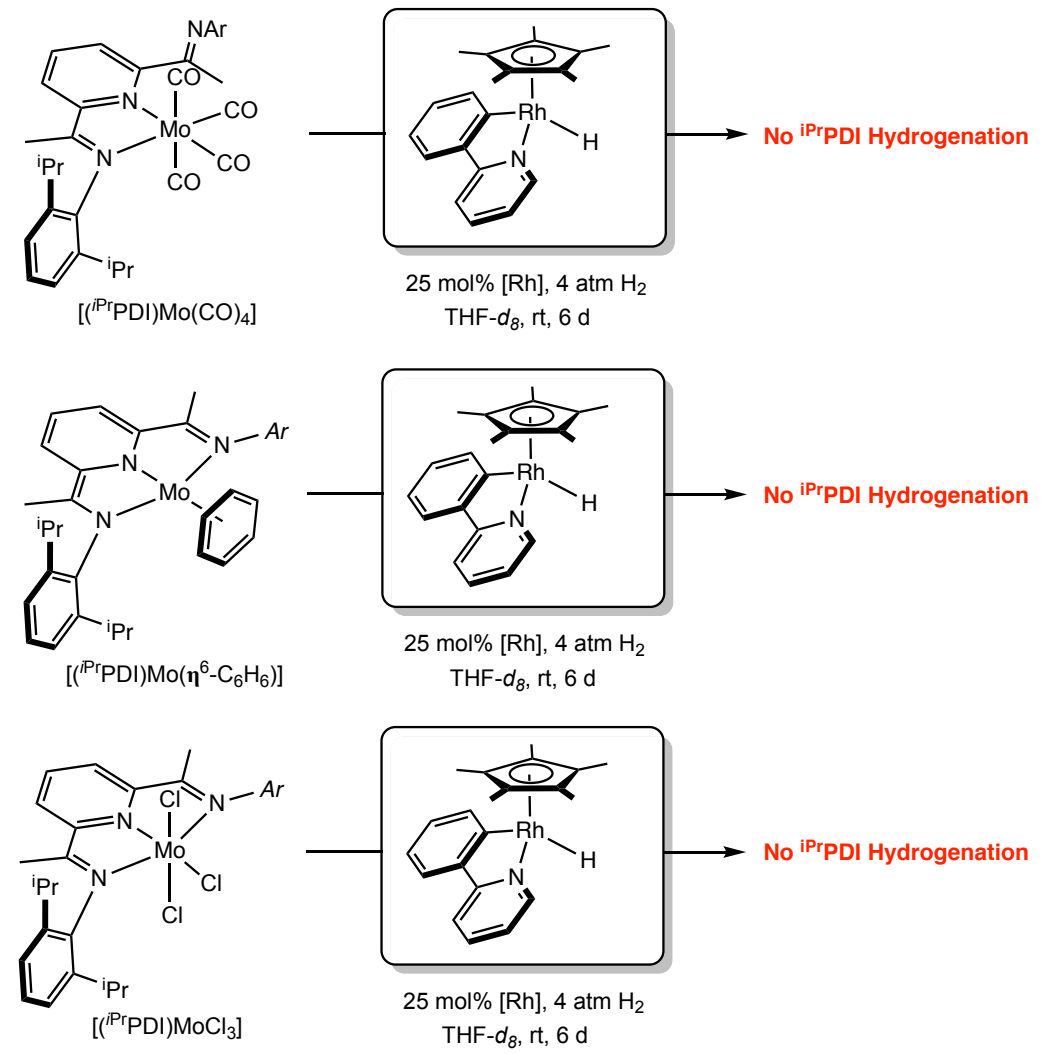

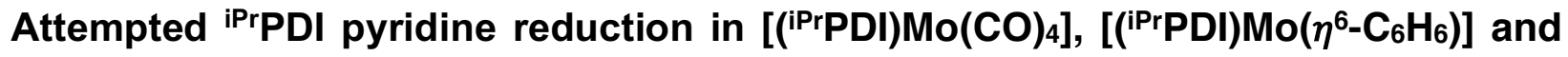
[( $\left.{ }^{\left(P_{r} P D I\right)} \mathrm{MoCl}_{3}\right]$. In the glovebox, a J-Young NMR tube fitted with a Teflon cap was charged with $0.061 \mathrm{mmol}$ of either $\left[\left({ }^{(\mathrm{Pr} P D I}\right) \mathrm{Mo}(\mathrm{CO})_{4}\right], \quad\left[\left({ }^{(\mathrm{Pr} P D I}\right) \mathrm{Mo}\left(\eta^{6}-\mathrm{C}_{6} \mathrm{H}_{6}\right)\right]$ or [(iPrPDI)MoCl 3 ], $0.006 \mathrm{~g}(0.015 \mathrm{mmol})$ of $[\mathrm{Rh}-\mathrm{H}]$ and $\left(0.001 \mathrm{~g}(0.005 \mathrm{mmol})\right.$ of a $\mathrm{Cp}_{2} \mathrm{Fe}$ internal standard dissolved in $0.3 \mathrm{~mL}$ THF- $d_{8}$. The tube was sealed and connected to the high vacuum line and frozen. The tube headspace was evacuated and $\mathrm{H}_{2}$ (1 atm at $-196{ }^{\circ} \mathrm{C} ; \sim 4$ atm at $23^{\circ} \mathrm{C}$ ) was admitted. The tube was sealed, rotated end-over-end at room temperature and monitored by ${ }^{1} \mathrm{H}$ NMR spectroscopy. In each case, no evidence

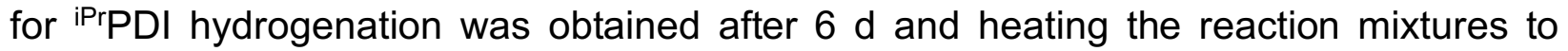
$60^{\circ} \mathrm{C}$ for $18 \mathrm{~h}$ yielded intractable product mixtures. 


\section{NMR Data}

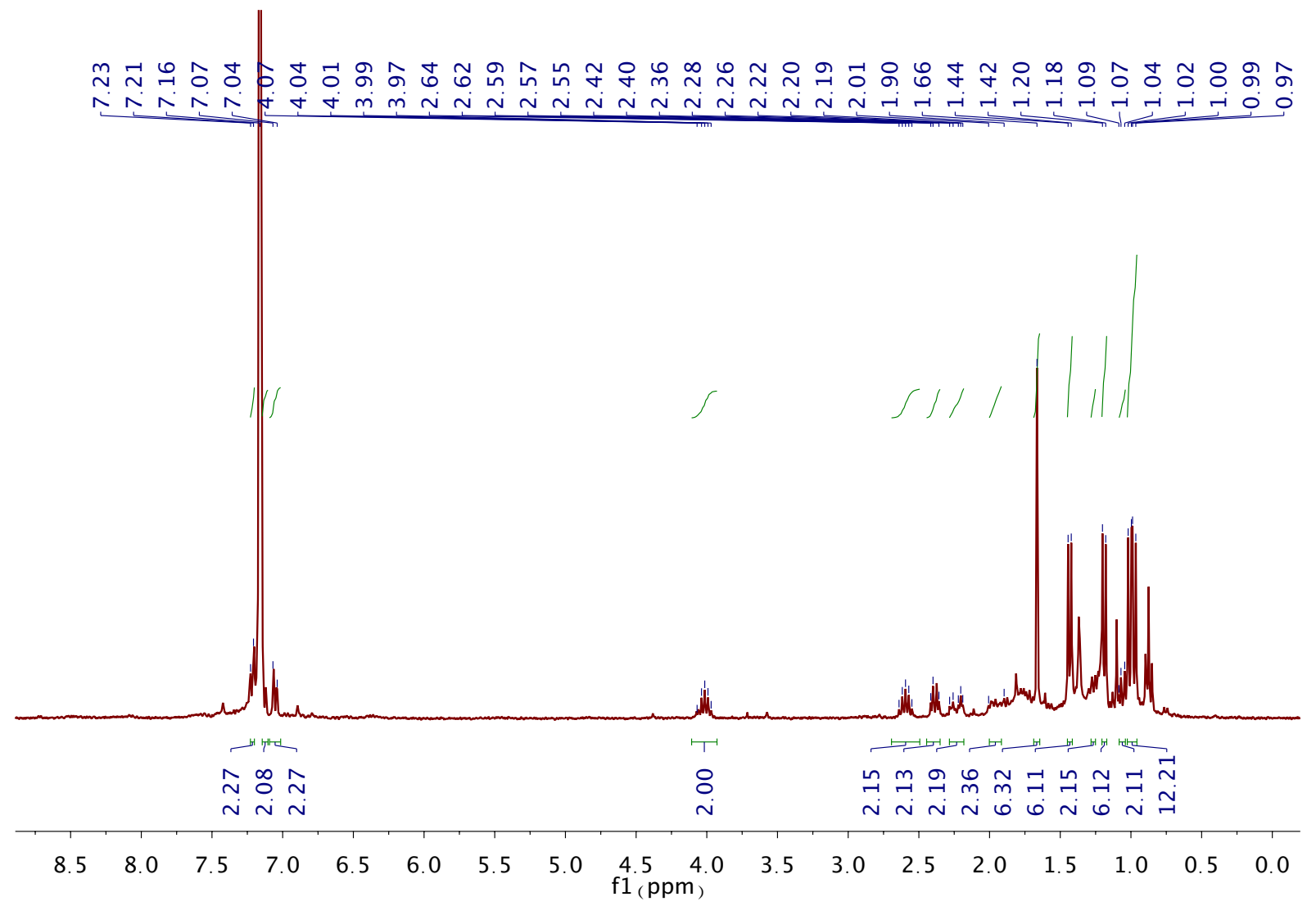

Figure S1. ${ }^{1} \mathrm{H}$ NMR $(500 \mathrm{MHz})$ spectrum of $\left[2-(\mathrm{N})\left(\eta^{2}-\mathrm{C}_{2} \mathrm{H}_{4}\right)\right]$ in benzene- $d_{6}$ at $23^{\circ} \mathrm{C}$. 


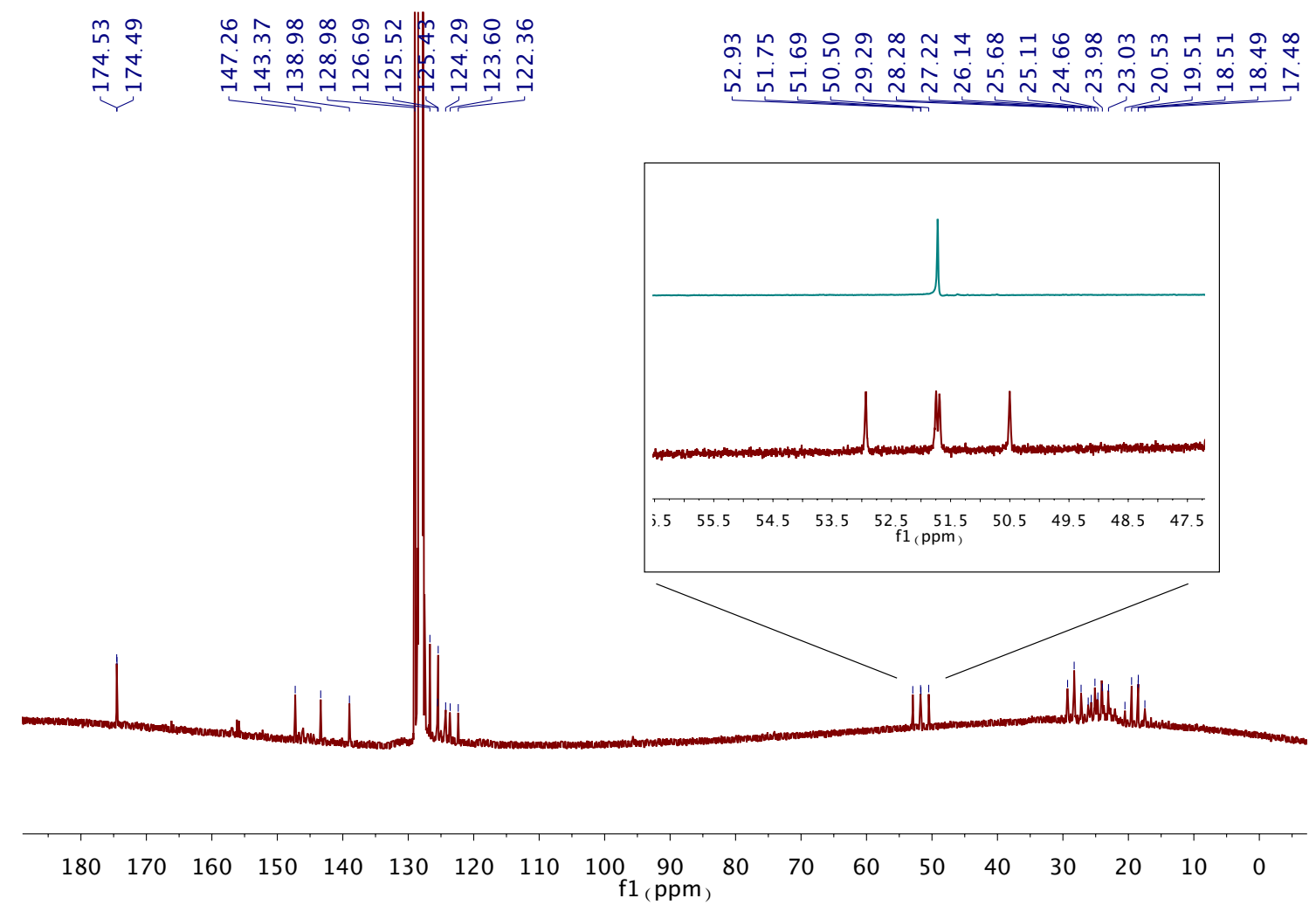

Figure S2. ${ }^{13} \mathrm{C}$ NMR spectrum of $\left[2-(\mathrm{N})\left(\eta^{2}-\mathrm{C}_{2} \mathrm{H}_{4}\right)\right]$ in benzene- $d_{6}$ at $23{ }^{\circ} \mathrm{C}$. Inset shows expanded view of ethylene ligand ${ }^{13} \mathrm{C}$ signal (bottom) overlaid with the corresponding ${ }^{13} \mathrm{C}\left\{{ }^{1} \mathrm{H}\right\}$ signal (top). ${ }^{1} \mathrm{~J}_{\mathrm{C}-\mathrm{H}}$ (ethylene) $=156.7,149.2 \mathrm{~Hz}$. 


\section{EPR Data}

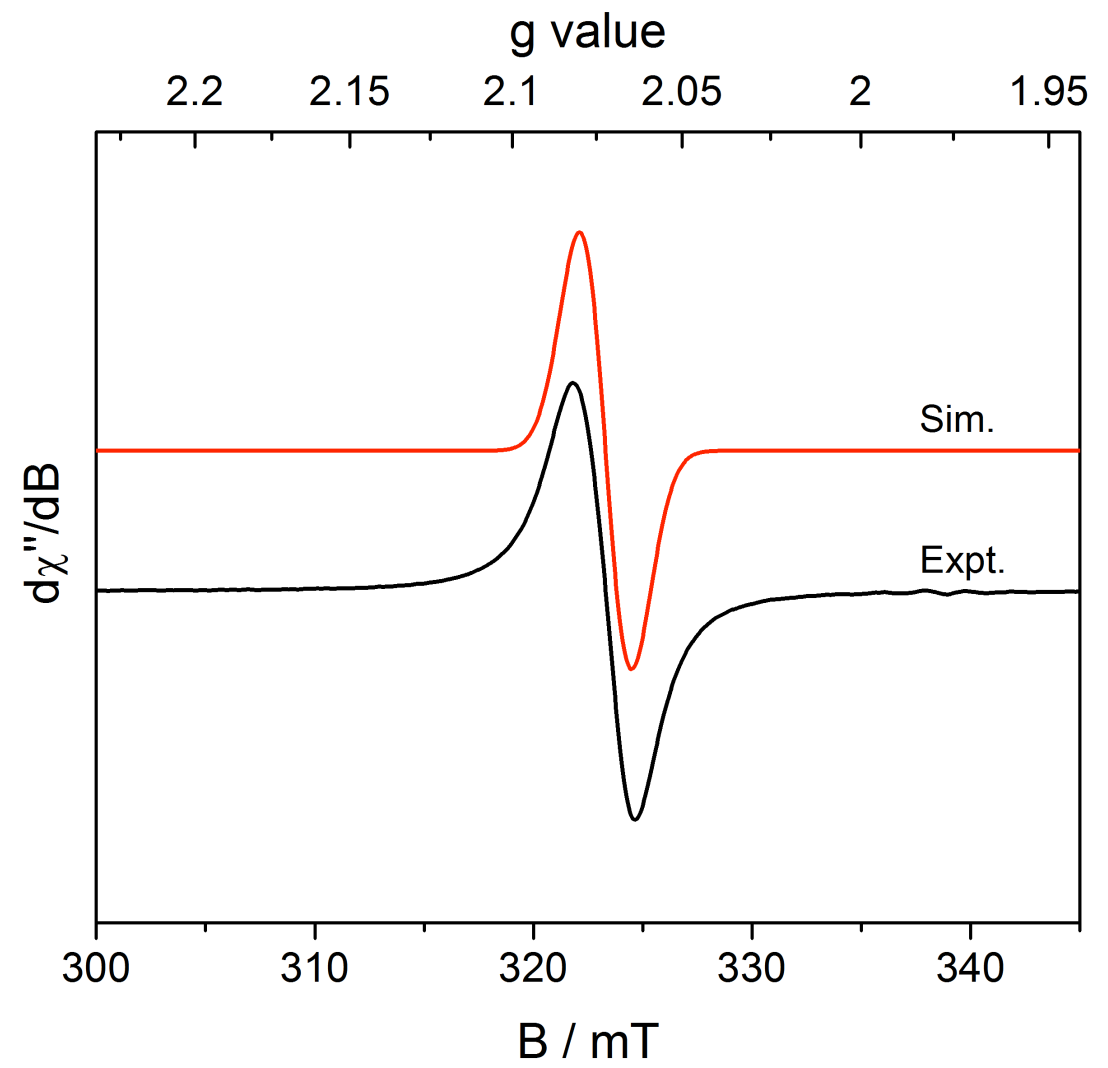

Figure S3. X-band EPR spectrum of $\left[\left(\eta^{5}-\mathrm{C}_{5} \mathbf{M e}_{5}\right)(\mathrm{py}-\mathrm{Ph}) \mathrm{Rh}\right]$ recorded at $23{ }^{\circ} \mathrm{C}$ in toluene solution (microwave frequency $=9.378 \mathrm{GHz}$, power $=2.00 \mathrm{~mW}$, power attenuation $=20.0 \mathrm{~dB}$, modulation amplitude $=4.000 \mathrm{G})$. Simulation of $\left[\left(\eta^{5}-\mathrm{C}_{5} \mathbf{M e}_{5}\right)(\mathrm{py}-\mathrm{Ph}) \mathrm{Rh}\right]: \mathrm{g}_{\text {iso }}=2.070$. 


\section{Electronic Absorption Data}

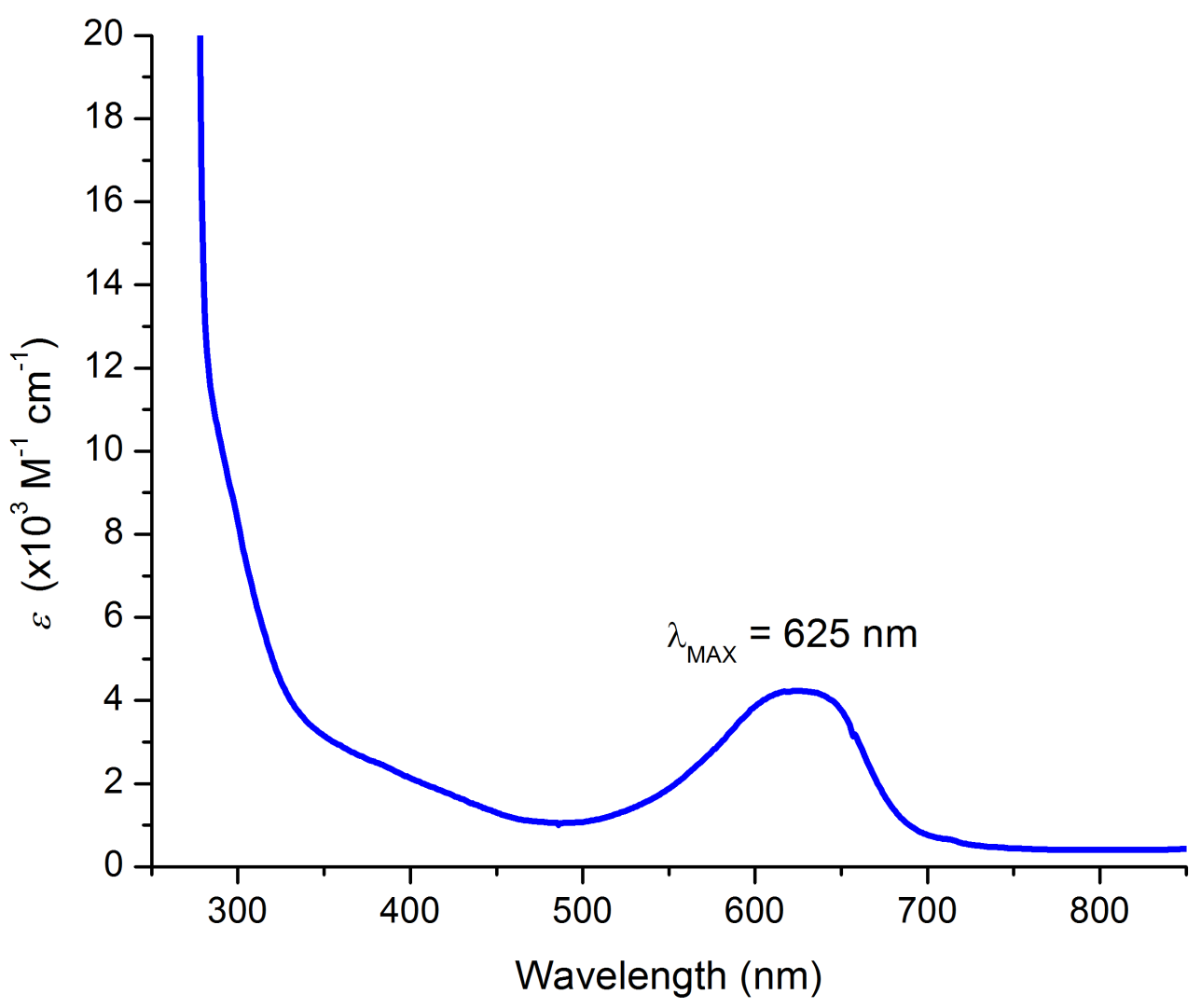

Figure S4. Electronic absorption spectrum of $\left[2-(\mathbf{N})\left(\eta^{2}-\mathbf{C}_{2} \mathrm{H}_{4}\right)\right]$ collected at $23{ }^{\circ} \mathrm{C}$ in toluene solvent. 


\section{Electronic Structure Discussion}

(a)
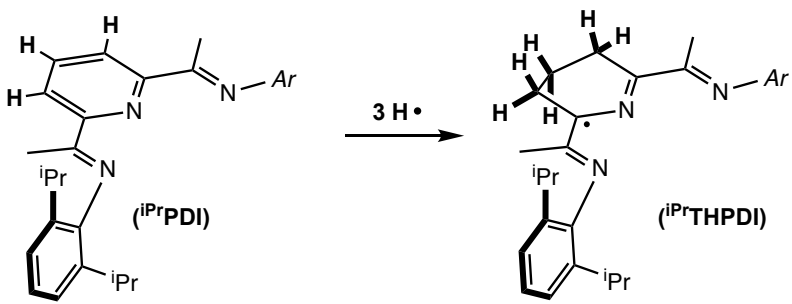

(b)

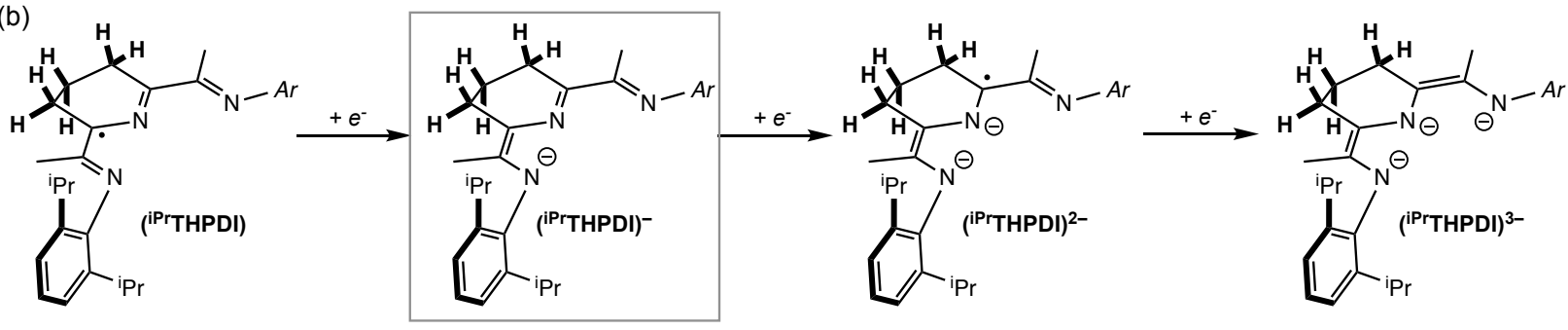

- Filled a" orbital, empty a' orbital

- Closed-shell, anionic ligand

Figure S5. (a) Addition of three hydrogen atom equivalents to ${ }^{\mathrm{PPr} P D I}$. (b) Potentially redox-active

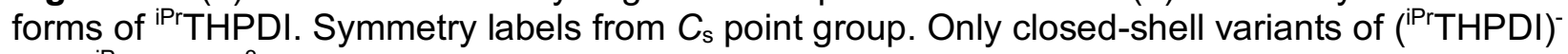
and (iPrTHPDI) ${ }^{3-}$ are depicted.

As shown in Figure S5a, addition of three $\mathrm{H}$-atom equivalents to a neutral ${ }^{\mathrm{Pr} P D I}$ ligand generates an ${ }^{\text {PrTHPDI }}$ chelate with an unpaired electron in its neutral form. Therefore, one- or three-electron ligand reductions are necessary to generate a closed-shell forms of iPrTHPDI. In analogy to iPrPDI, two $\pi^{*}$ orbitals of a" and a' symmetry are available to accommodate redox events at the ligand. ${ }^{16}$ Computation of occupied and unoccupied a" and a' orbitals, respectively, together with the overall diamagnetism of [2-(N)( $\left.\mathbf{n}^{2}-\mathbf{C}_{2} \mathbf{H}_{4}\right)$ ] support a closed shell, anionic iPrTHPDI chelate (Figure S5b). Broken-symmetry solutions were not located for $\left[2-(\mathbf{N})\left(\mathbf{n}^{2}-\mathbf{C}_{2} \mathbf{H}_{4}\right)\right]$ and therefore a diradical, anionic

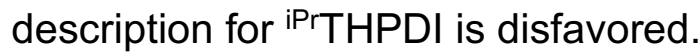




\section{DFT Input Example}

\# Filename

! RKS B3LYP RIJCOSX ZORA ZORA-def2-SVP SARC/J Normalprint SlowConv TightOpt NUMFREQ GRID5 FINALGRID6 GRIDX4 Pal8 UCO

\%basis NewGTO 42 "old-ZORA-TZVP" end NewGTO 7 "ZORA-DEF2-TZVP(-f)" end NewAuxGTO 42 "SARC/J" end NewAuxGTO 7 "SARC/J" end end

\%SCF MaxIter 1500 Convergence VeryTight end

\%FREQ RESTART TRUE CENTRALDIFF TRUE INCREMENT 0.01 END

${ }^{*}$ xyz 01

XYZ Coordinates

*

\%plots format cube $\operatorname{dim} 1100 \operatorname{dim} 2100 \operatorname{dim} 3100$ SpinDens("filename.cube"); end 


\section{DFT-Computed Energies}

Table S1. Calculated Gibbs free energies of molybdenum complexes for $\mathrm{C}-\mathrm{H}$ BDFE determinations. Bolded compounds refer to those with experimentally known spin states. For intermediates, both low-spin ( $S=0$ or $1 / 2)$ and high spin $(S=1$ or $3 / 2$ ) configurations were examined, and the results for lowest energy spin-states are reported.

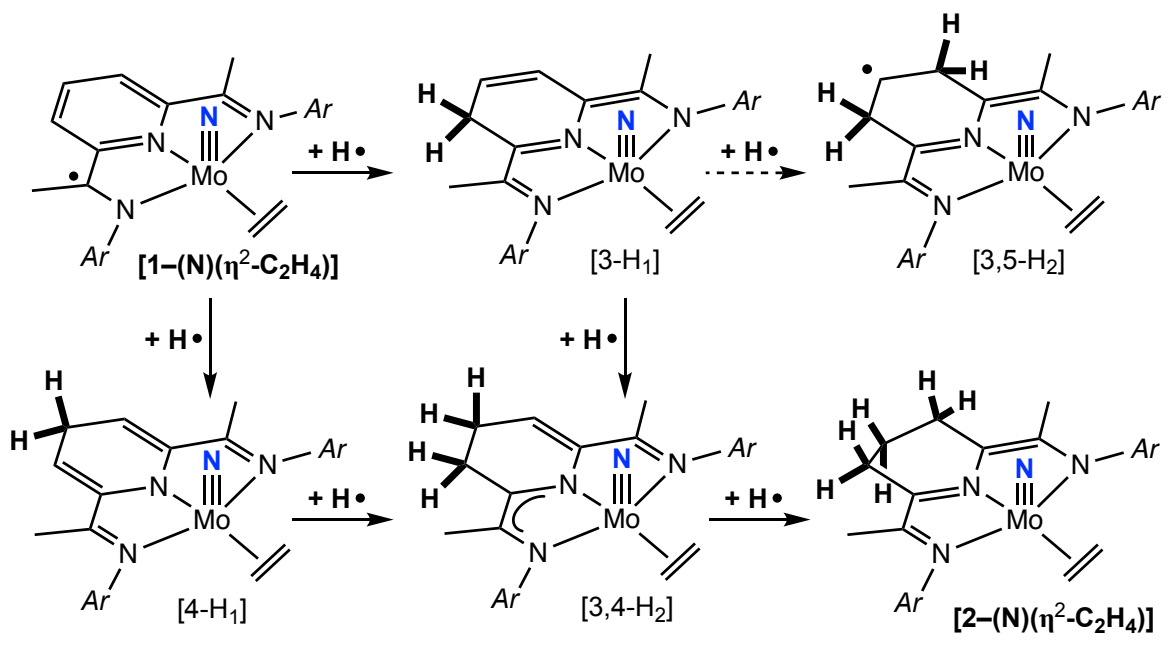

\begin{tabular}{cccr} 
Compound & Spin State & $\begin{array}{l}\text { Calculated Gibbs Free } \\
\text { Energy (Eh; B3LYP) }\end{array}$ & $\begin{array}{r}\text { Calculated Gibbs Fre } \\
\text { Energy (Eh; PW6B95 }\end{array}$ \\
\hline$\left[1-(\mathbf{N})\left(\eta^{2}-\mathbf{C}_{2} \mathrm{H}_{4}\right)\right]$ & $\mathbf{S}=\mathbf{1 / 2}$ & -5667.68508342 & -5672.47825649 \\
{$\left[3-\mathrm{H}_{1}\right]$} & $S=0$ & -5668.26188533 & -5673.05847862 \\
{$\left[4-\mathrm{H}_{1}\right]$} & $S=0$ & -5668.25896789 & -5673.05545464 \\
{$\left[3,4-\mathrm{H}_{2}\right]$} & $S=1 / 2$ & -5668.85108690 & -5673.64711609 \\
{$\left[3,5-\mathrm{H}_{2}\right]$} & $S=1 / 2$ & -5668.81056393 & -5673.60682903 \\
{$\left[2-(\mathbf{N})\left(\eta^{2}-\mathbf{C}_{2} \mathrm{H}_{4}\right)\right]$} & $\mathbf{S}=\mathbf{0}$ & -5669.45821065 & -5674.25654368
\end{tabular}




\section{References}

1 Pangborn, A. B.; Giardello, M. A.; Grubbs, R. H.; Rosen, R. K.; Timmers, F. J. Safe and Convenient Procedure for Solvent Purification. Organometallics 1996, 15, 1518-1520.

2 Margulieux, G. W.; Bezdek, M. J.; Turner, Z. R.; Chirik, P. J. Ammonia Activation, $\mathrm{H}_{2}$ Evolution and Nitride Formation from a Molybdenum Complex with a Chemically and Redox Noninnocent Ligand. J. Am. Chem. Soc. 2017, 139, 6110- 6113.

$3 \mathrm{Hu}$, Y.; Li, L.; Shaw, A. P.; Norton, J. R.; Sattler, W.; Rong, Y. Synthesis, Electrochemistry, and Reactivity of New Iridium(III) and Rhodium(III) Hydrides. Organometallics 2012, 31, 5058-5064.

4 Stoll, S.; Schweiger, A. EasySpin, a comprehensive software package for spectral simulatioin and analysis in EPR. J. Magn. Reson. 2006, 178, 42-55.

5 Neese, F. The ORCA program system. Wiley Interdiscip. Rev.: Comput. Mol. Sci. 2012, 2, 73-78.

6 (a) Becke, A. D. Density functional calculations of molecular bond energies. J. Chem. Phys. 1986, 84, 4524-4529. (b) Becke, A. D. Density-functional thermochemistry. III. The role of exact exchange. J. Chem. Phys. 1993, 98, 5648-5652. (c) Lee, C. T.; Yang, W. T.; Parr, R. G. Development of the Colle-Salvetti correlation-energy formula into a functional of the electron density. Phys. Rev. B. 1998, 37, 785-789.

7 Zhao, Y.; Truhlar, D. G. Design of Density Functions that Are Broadly Accurate for Thermochemistry, Thermochemical Kinetics, and Nonbonded Interactions. J. Phys. Chem. A 2005, 109, 5656- 5667.

8 (a) Schäfer, A.; Horn, H.; Ahlrichs, R. Fully optimized contracted Gaussian basis sets for atoms Li to Kr. J. Chem. Phys. 1992, 97, 2571-2577. (b) Schäfer, A.; Huber, C.; Ahlrichs, R. Fully optimized contracted Gaussian basis sets of triple zeta valence quality for atoms Li to Kr. J. Chem. Phys. 1994, 100, 5829-5835. (c) Weigend, F.; Ahlrichs, R. Balanced basis sets of split valence, triple zeta valence and quadruple zeta valence quality for $\mathrm{H}$ to Rn: Design and assessment of accuracy. Phys. Chem. Chem. Phys. 2005, 7, 3297-3305.

9 (a) Neese, F.; Wennmohs, F.; Hansen, A.; Becker, U. Efficient, Approximate and parallel Hartree-Fock and hybrid DFT calculations. A 'chain-of-spheres' algorithm for the Hartree-Fock exchange. Chem. Phys. 2009, 356, 98-109. (b) Kossmann, S.; Neese, F. Comparison of two efficient approximate Hartee-Fock approaches. Chem. Phys. Lett. 2009, 481, 240-243. (c) Neese, F. An improvement of the resolution of the identity approximation for the formation of the Coulomb matrix. J. Comput. Chem. 2003, 24, 1740-1747.

10 (a) Eichkorn, K.; Weigend, F.; Treutler, O.; Ahlrichs, R. Auxiliary basis sets for main row atoms and transition metals and their use to approximate Coulomb potentials. Theor. Chem. Acc. 1997, 97, 119-124. (b) Eichkorn, K.; Treutler, O.; Öhm, H.; Häser, m.; Ahlrichs, R. Auxiliary basis sets to approximate Coulomb potentials. Chem. Phys. Lett. 1995, 240, 283-289. (c) Eichkorn, K.; Treutler, O.; Öhm, H.; Häser, M.; Ahlrichs, R. 
Auxiliary basis sets to approximate Coulomb potentials. Chem. Phys. Lett. 1995, 242, 652-660.

11 van Wullen, C. Molecular density functional calculations in the regular relativistic approximation: Method, application to coinage metal diatomics, hydrides, fluorides and chlorides, and comparison with first-order relativistic calculations. J. Chem. Phys. 1998, 109, 392-399.

12 Weigend, F.; Ahlrichs, R. Balanced basis sets of split valence, triple zeta valence and quadruple zeta valence quality for $\mathrm{H}$ to Rn: Design and assessment of accuracy. Phys. Chem. Chem. Phys. 2005, 7, 3297-3305.

13 Thom, A. J. W.; Sundstrom, E. J.; Head-Gordon, M. LOBA: A localized orbital bonding analysis to calculate oxidation states, with application to a model water oxidation catalyst. Phys. Chem. Chem. Phys. 2009, 11, 11297-11304.

14 Lu, T.; Chen, F. Multiwfn: A multifunctional wavefunction analyzer. J. Comput. Chem. 2012, 33, 580-592.

15 Cosquer, N.; Le Gall, B.; Conan, F.; Kerbaol, J.-M.; Sala-Pala, J.; Kubicki, M. M.; Vigier, E. Carbonylmolybdenum complexes with di(imino)pyridine and related ligands: Reduction of a di(imino)pyridine to an aminoiminopyridine system under mild conditions. Inorg. Chim. Acta 2006, 359, 4311-4316.

16 Bart, S. C.; Chłopek, K.; Bill, E.; Bouwkamp, M. W.; Lobkovsky, E.; Neese, F.; Wieghardt, K.; Chirik, P. J. Electronic Structure of Bis(Imino)Pyridine Iron Dichloride, Monochloride, and Neutral Ligand Complexes: A Combined Structural, Spectroscopic, and Computational Study. J. Am. Chem. Soc. 2006, 128, 13901-13912. 